\title{
Cosmetotextiles: A novel technique of developing wearable skin care
}

\author{
MAMTA, HARMINDER KAUR SAINI AND MANIDEEP KAUR
}

Received: 01.03.2017; Accepted: 26.05.2017

See end of the paper for authors' affiliations

\section{MAMTA}

Department of Apparel and Textile

Science, College of Home Science,

Punjab Agricultural University,

LUDHIANA (PUNJAB) INDIA

Email : mamtagbpuatpantnagar@

gmail.com
ABSTRACT : Clothes have always fulfilled a variety of functions - be it fashion, warmth, protection and support. With the growing trend in enhancing beauty through healthy means, customers request for apparels and home textiles containing not only their original basic characteristics, such as warmth and comfort, but also ones that carry extra functions, including cleaning, perfuming, changing appearance, protection, or correction of body odors and keeping the more natural and healthier life. Cosmetotextile is a concept of releasing cosmetic ingredient to the human skin. Though the term "Cosmetotextiles" is new but it originated from Ayurveda which is an ancient medical treatise, summarizing the art of healing and is practiced in India for more than 5,000 years. The technology of Cosmetotextile is at the neonatal stage. On contact with human body and skin, Cosmetotextiles are designed to transfer an active substance for cosmetic purposes. The principle is achieved by simply imparting the cosmetic and pharmaceutical ingredients into the fabric of the clothing so that with the natural movements of the body, the skin is slowly freshened, revitalized or cured according to the ingredient used.

KEY WORDS: Ayurvastra, Cosmetic, Herb, Microencapsulation, Textile

- HOW TO CITE THIS PAPER : Mamta, Saini, Harminder Kaur and Kaur, Manideep (2017). Cosmetotextiles: A novel technique of developing wearable skin care. Asian J. Home Sci., 12 (1) : 289-295, DOI: 10.15740/HAS/AJHS/12.1/289-295. 